\title{
Control of PWM rectifier under grid voltage dips
}

\author{
M. BOBROWSKA-RAFAŁ ${ }^{1 *}$, K. RAFAŁ $^{1}$, G. ABAD ${ }^{2}$, and M. JASIŃSKI ${ }^{1}$ \\ ${ }^{1}$ Institute of Control and Industrial Electronics, Warsaw University of Technology, 75 Koszykowa St., 00-662 Warsaw, Poland \\ ${ }^{2}$ Electronics and Computing Department, Mondragon Unibertsitatea - Faculty of Engineering, \\ Loramendi, 4;20500 Arrasate-Mondragón, Spain
}

\begin{abstract}
This paper investigates control structure for grid connected three-phase two-level Voltage Source Converter (VSC) under distorted grid voltage conditions. Grid voltage is distorted by balanced and unbalanced voltage dips and higher harmonics. To address the problem, the control structure of converter is presented. The control system is a modification of Voltage Oriented Control (VOC) based on Dual Vector Current Controllers (DVCC). Grid synchronization under distorted voltage is achieved by employing Phase Locked Loop (PLL). Simulation and experimental results, which illustrate properties of proposed system, are presented.
\end{abstract}

Key words: PWM rectifier, voltage source converters, voltage oriented control, renewable energy, voltage dips.

\section{Introduction}

The proper operation of electrical devices is determined by grid voltage conditions. It is well known, that grid voltage is not free from disturbances. Voltage deviations, like voltage amplitude drop, frequency deviations and higher harmonic components, cause inappropriate functioning of several electronic devices. Balanced and unbalanced voltage dips make the system unstable and cause serious deviation to the shape of currents [1]. Depending on severity of disturbance and properties of device voltage variations can lead to cutting of the operation or even destruction of device, causing financial losses. There are strict directives according to voltage distortions occurred in power system. The European regulation [2] allows $6 \%$ low order supply voltage harmonics and supply voltage dips within $10 \%$.

On the other hand, there are strict requirements for quality of power supplied to the grid by renewable energy sources. Many countries introduce specific regulations called grid codes [3]. The most important requirements imposed by them are:

- Fault ride trough capability - device must stay disconnected and inject reactive power to the grid while voltage dip of specific time and depth appears,

- Current quality - current drawn by renewable energy sources must be balanced and have low harmonic content (usually THD factor below 5\%),

- Frequency deviations - device must stay disconnected if grid voltage frequency varies between specific limits.

As renewable energy sources are usually connected to the grid through power electronic converters it is the matter of control algorithm to fulfill these requirements.

The Pulse Width Modulated (PWM) Voltage Source Converters (VSC) has gained popularity last years. They are employed for high-performance applications because of its si- nusoidal input current with unity power factor, bidirectional power flow capability, operation with respectively small current variations, constant and controlled dc link voltage and a small output filter capacitor [4]. However, they are not immune to grid voltage dips and harmonics. When VSC operates under distorted voltage, currents are also polluted by higher harmonics and/or increased amplitude.

For VSC the most popular are three basic control algorithms: Voltage Oriented Control (VOC) [4], Direct Power Control (DPC) [5] and their combination DPC-SVM [6]. Recently, thanks to availability of fast and powerful microprocessor systems also Model Predictive Control (MPC) algorithms have gained interest [7, 8]. However, the most often used is the VOC algorithm. Each of depicted control method does not assure total immunity on grid voltage distortions. Many improvements were proposed to face the problem of grid voltage distortion. Among them are: Virtual Flux Oriented Control [9], Multi-reference Control [10], Resonant Controllers [11], dc bus voltage optimization [12] and others $[13,14]$, and many methods for higher harmonics compensation.

In this paper, the improved Voltage Oriented Control algorithm basing on Dual Vector Current Control (DVCC) $[15,16]$ is presented. The control algorithm, dedicated to the VSC mitigates the influence of voltage dips and high order harmonic components. Improved VOC algorithm assures sinusoidal shape of current under any type of voltage dip in the grid. Principle of the method, simulation and experimental results are presented in this paper.

\section{Voltage dips in power system}

No matter, how stiff is the transmission and distribution system, the voltage disturbance can occur due to different reasons. Nowadays, the most serious problems concerning power systems are higher harmonics and voltage dips. Voltage dip

*e-mail: bobrowsm@isep.pw.edu.pl 
is a short-term reduction or complete loss of voltage or/and a phase-angle jump. It is specified in terms of duration and retained voltage, usually expressed as the percentage of nominal RMS voltage [1]. There are three main reasons of dips forming:

- short-circuits faults in different points of the power system,

- starting of large loads (e.g. high power drives),

- Non-linear loads connected to power system.

These situations, occurring in a system, can cause balanced as well as unbalanced voltage dips. Unbalance is phenomenon appearing in a three-phase system, in which RMS values of the voltages or the phase angles between consecutive phases are not equal.

There are different types of voltage dips. Classification of four most typical dip types can be distinguished [1] as it is presented in Fig. 1. If a voltage dip appears in the system it can change to another type due to load connection, transfer to lower voltage (depending on transformer connection) level or others.

To analyze the dip phenomena, the Symmetrical Component Theory $[17,18]$ was employed. It claims that three-phase system can be represented as three sequences: positive, negative and zero. In three-wire system, which is applied to most VSC's zero sequence does not appear. For balanced system voltage has only positive sequence component. When an unbalanced dip occurs a negative component appears causing large unbalance to the system.

a)

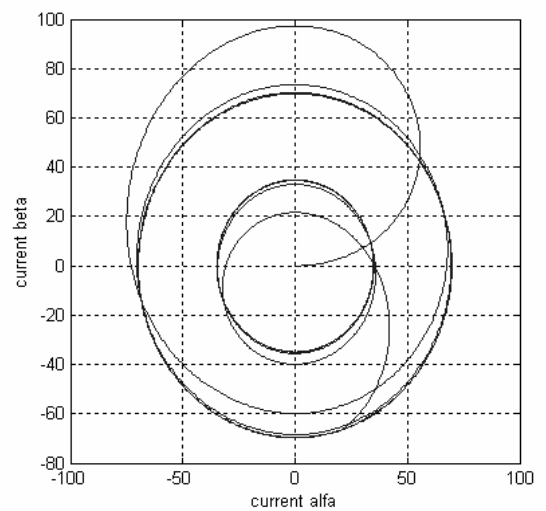

b)

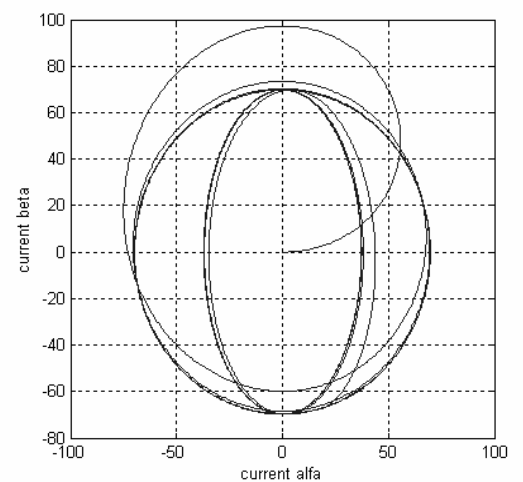

Type A

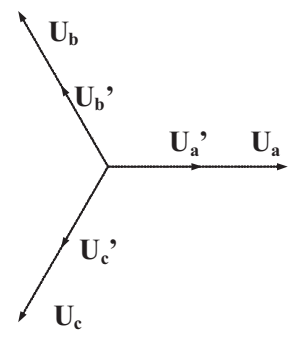

Type $\mathbf{C}$

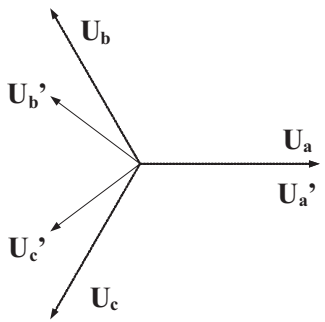

Type $\mathbf{B}$

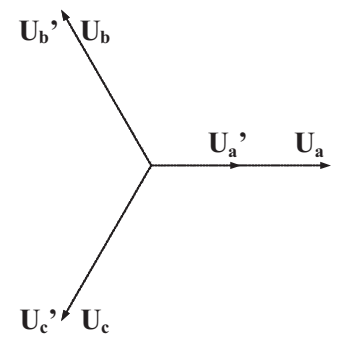

Type $\mathbf{D}$

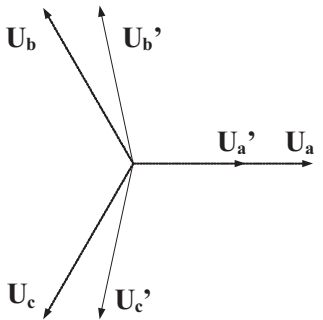

Fig. 1. Phasor representation of four basic voltage dip types

For system analysis the Space Vector method [19] was used. It represents three-phase quantities as a vector in $\alpha \beta$ plane. It simplifies calculations and provides concise representation of the system. In balanced system a vector trajectory is circular, while for unbalanced case it turns elliptic (Fig. 2). In this case a space vector can also be represented as a sum of two components rotating clockwise and counterclockwise.
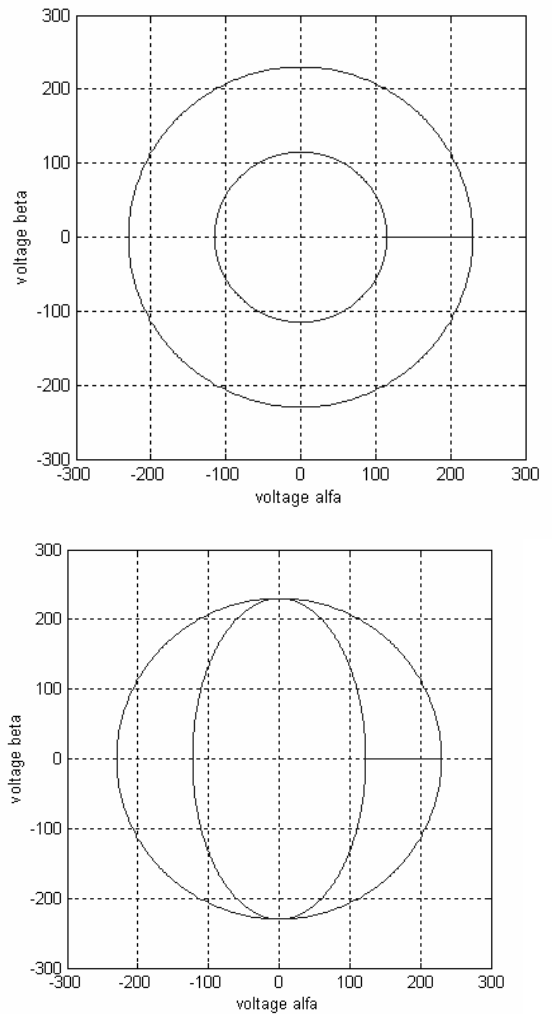

Fig. 2. Current and voltage space vectors during voltage dip a) dip type A; b) dip type B 


\section{Control of AC-DC converter under grid voltage dips}

The negative component produces current disturbances and causes large unbalance to the AC-DC converter. The proper operation of the grid side AC-DC converter, under distorted voltage conditions, is strongly dependent on the implemented control algorithm. A Control algorithm, operating under balanced and unbalanced voltage dips, must face following problems:

- Line current distortion,

- De link oscillations,

- Variations of phase angle and phase angle jumps,

- Variations of voltage amplitude,

- Unstable power factor,

- Higher harmonics content in grid system.

The basic control system is designed assuming balanced grid voltage and it has a lot of difficulties to deal with the proper control of the negative sequence. To meet aforementioned problems, improved VOC algorithm, based on Dual Vector Current Controller, is presented in this paper. In this control algorithm two independent current controllers, working in positive and negative Synchronous Reference Frames (SRF), are employed to control both current sequences independently. Current signals are transformed from natural $a b c$ quantities to $d q$ frame rotating synchronously with grid voltage vector. In SRF currents occur as dc values in their frames, so there is no need to build a tracking controller and PI controller is a sufficient solution.

Symmetrical components theory refers to phasor calculations at steady state, while control algorithm operates on instantaneous values. Therefore, to implement improved VOC, both voltage and current real-time sequences extraction method is needed. Calculated current sequences are controlled in their respective reference coordinates. In stationary $\alpha \beta$ coordinates unbalanced current vector is represented by two components:

$$
\vec{i}_{\alpha \beta}(t)=\overrightarrow{i^{+}} e^{j \omega t}+\overrightarrow{i^{-}} e^{-j \omega t},
$$

where $i_{\alpha \beta}$ - current vector in stationary frame, $i^{+}$- positive sequence vector, $i^{-}$- negative sequence vector.

After the transformation to SRF's current sequences can be represented as:

$$
\begin{aligned}
& \vec{i}_{d q}^{+}(t)=\overrightarrow{i^{+}}+\overrightarrow{i^{-}} e^{-j 2 \omega t}, \\
& \vec{i}_{d q}^{-}(t)=\overrightarrow{i^{-}}+\overrightarrow{i^{+}} e^{-j 2 \omega t},
\end{aligned}
$$

where $\mathrm{i}_{d q}^{+}$- current vector in frame rotating with grid voltage vector, $\mathrm{i}_{d q}^{-}-$current vector in frame rotating in opposite direction.

The positive sequence appears as a dc value in positive SRF and as a $100 \mathrm{~Hz}$ component in negative SRF. The same occurs for the negative sequence appearing as a dc value in negative SRF and as $100 \mathrm{~Hz}$ in positive SRF. By removing double frequency components both current sequences can be calculated. Low-pass filters have been tested for this purpose, however they caused instability problems. Finally to remove double frequency component Delayed Signal Cancellation (DSC) method is employed [18]. The DCS is the realtime sequence extraction method, based on combination of time delayed synchronous frame magnitudes. To actual signals in SRF, the signal delayed by quarter period is added. This simple method to remove $100 \mathrm{~Hz}$ component from a dc signal and it is applied for both $d$ and $q$ current components in positive and negative SRF. The DSC algorithm is described by following equation:

$$
i_{D S C}(t)=\frac{\left(i(t)+i\left(t-\frac{T}{4}\right)\right)}{2},
$$

where $T$ - fundamental grid voltage period.

For proper operation the improved VOC algorithm must be capable to detect the phase angle of grid voltage in order to synchronize the output signals. The information about value of phase angles is extremely important for proper signal transformations used in control algorithm. Usually, the arctan function is applied to voltage space vector to obtain the phase angle information. In situation, when grid voltage is disturbed, the phase angle produced in such a way is also distorted (Fig. 3a shows phase angle calculated during voltage dip type B). It leads to transporting the distortion to control algorithm, which cannot operate properly. The solution is improved Phase Locked Loop (PLL) algorithm, operating in $d q$ synchronously rotating coordinates (Fig. 3c). The phase angle estimated by PLL is presented in Fig. 3b. Perturbation caused by negative sequence component is mitigated and generated phase angle is stable.

a)

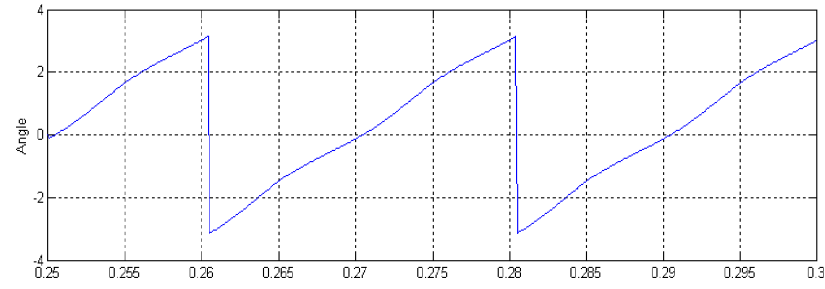

b)

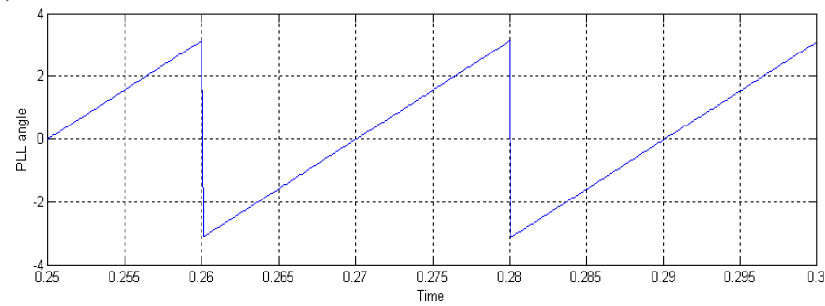

c)

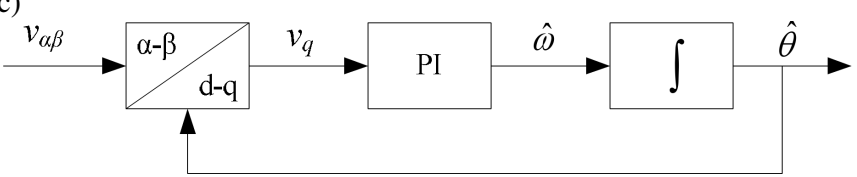

Fig. 3. a) Phase angle calculated using arctan, b) phase angle calculated using PLL, c) Phase Locked Loop algorithm 


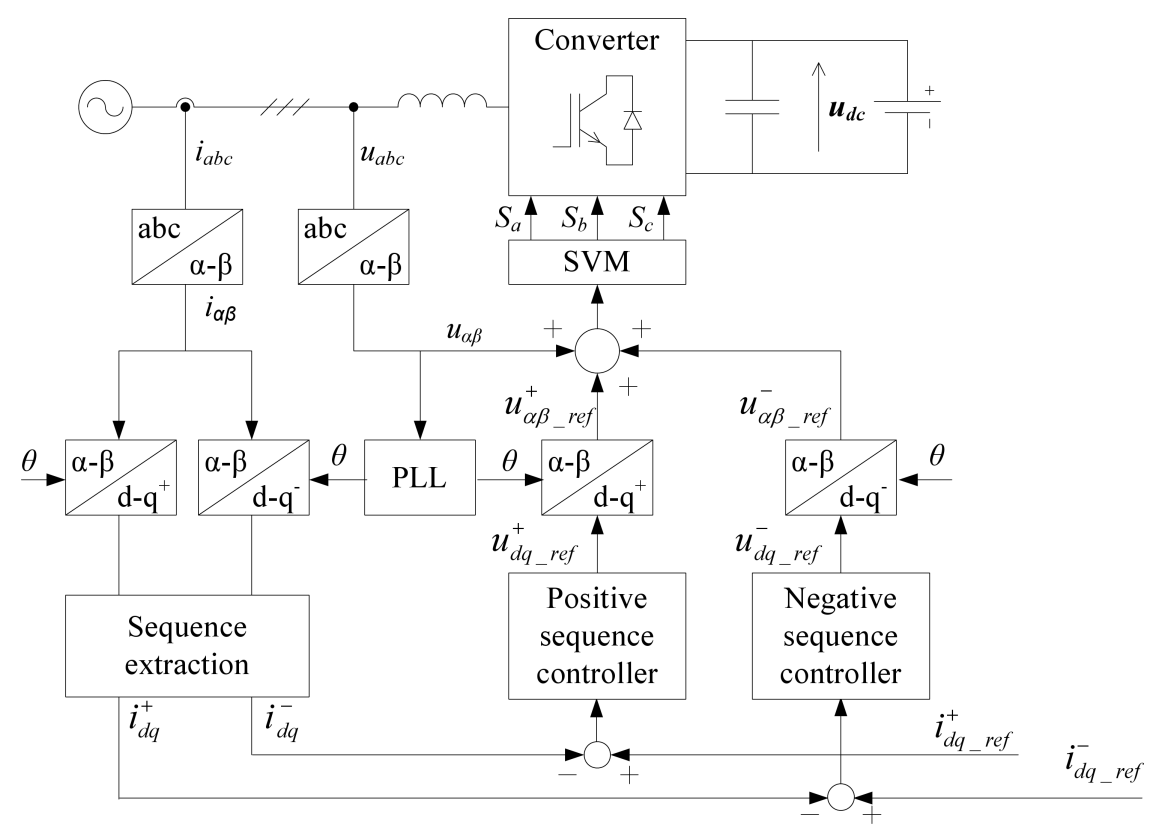

Fig. 4. Dual Vector Current Controller scheme

To speed up the operation of control and compensation impact, a feedforward line voltage loop could be added. During the experimental part different grid voltages feedforward were examined, like the natural, stationary and synchronous components feedforward. The best results are obtained with the $\alpha \beta$ component feedforward. To calculated, by control algorithm, reference signals transferred to Space Vector Modulator (SVM), the actual voltage signals in $\alpha \beta$ coordinates are added. The feedforward mitigates the influence of different harmonic components and, as result improves the operating of whole system by cancelling undesired signals. However, when there are no grid voltage sensors it cannot be applied.

Connecting all parts of control algorithm: DVCC, PLL, DSC sequence extraction and optionally voltage feedforward, the improved VOC scheme is presented in Fig. 4.

\section{Selected experimental results}

Improved VOC algorithm was experimentally validated using PWM converter with dSPACE 1103 based control platform. Scheme and main parameters of the test-bench used to carry out the experimental tests are presented in Fig. 5 and Table 1.
Table 1

Rated values of the experimental test-bench

\begin{tabular}{cc}
\hline \hline Rated values of the experimental test-bench \\
\hline Current & $10 \mathrm{~A}$ \\
Grid voltage & $230 \mathrm{~V}$ \\
DC bus voltage & $600 \mathrm{~V}$ \\
Line filter inductance & $10 \mathrm{mH}$ \\
Switching frequency & $10 \mathrm{kHz}$ \\
\hline
\end{tabular}

All the following tests are carried out under single phase $30 \%$ depth voltage dip and non-sinusoidal grid voltage. Extracted voltage components in both SRF's are presented in Fig. 6. It can be noticed, that under unbalanced voltage the negative sequence appears. Current reference is set to $10 \mathrm{~A}$ magnitude of active current in positive SRF. Figure 7 presents results captured in the laboratory to compare conventional and improved VOC algorithms. Simple VOC is not capable of dealing with negative sequence and oscillations appear in controlled current values, while improved algorithm provides steady operation. Moreover, introduced voltage feedforward deals with higher voltage harmonics. Under highly distorted voltage shape current remains sinusoidal as shown in Fig. 8.

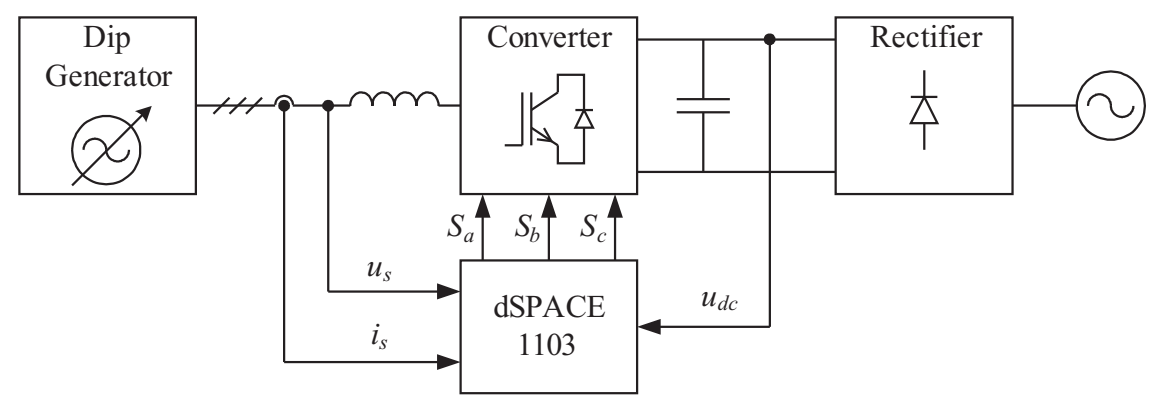

Fig. 5. Experimental setup scheme 

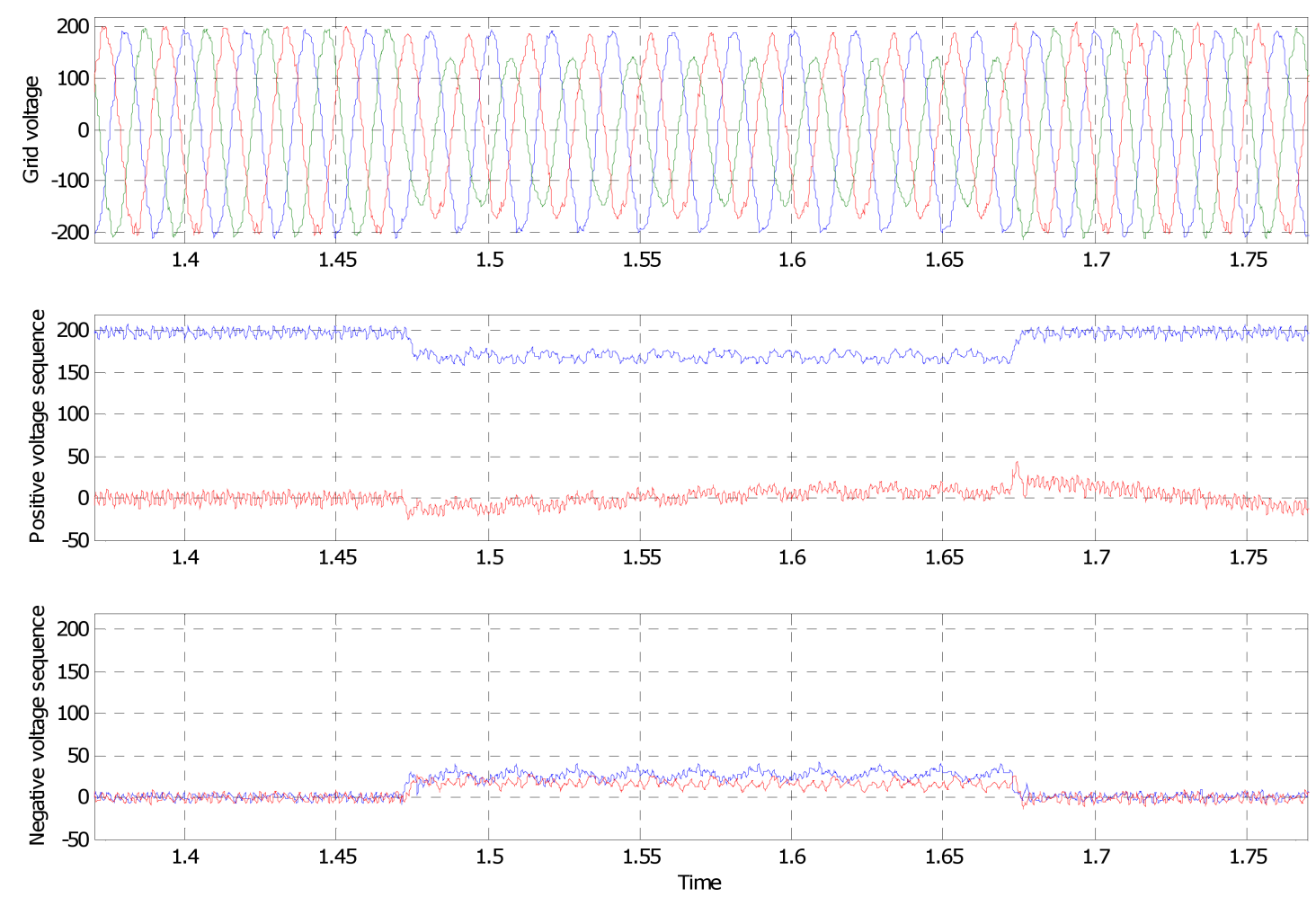

Fig. 6. Experimental one phase voltage dip for control system testing and extracted positive and negative voltage sequence
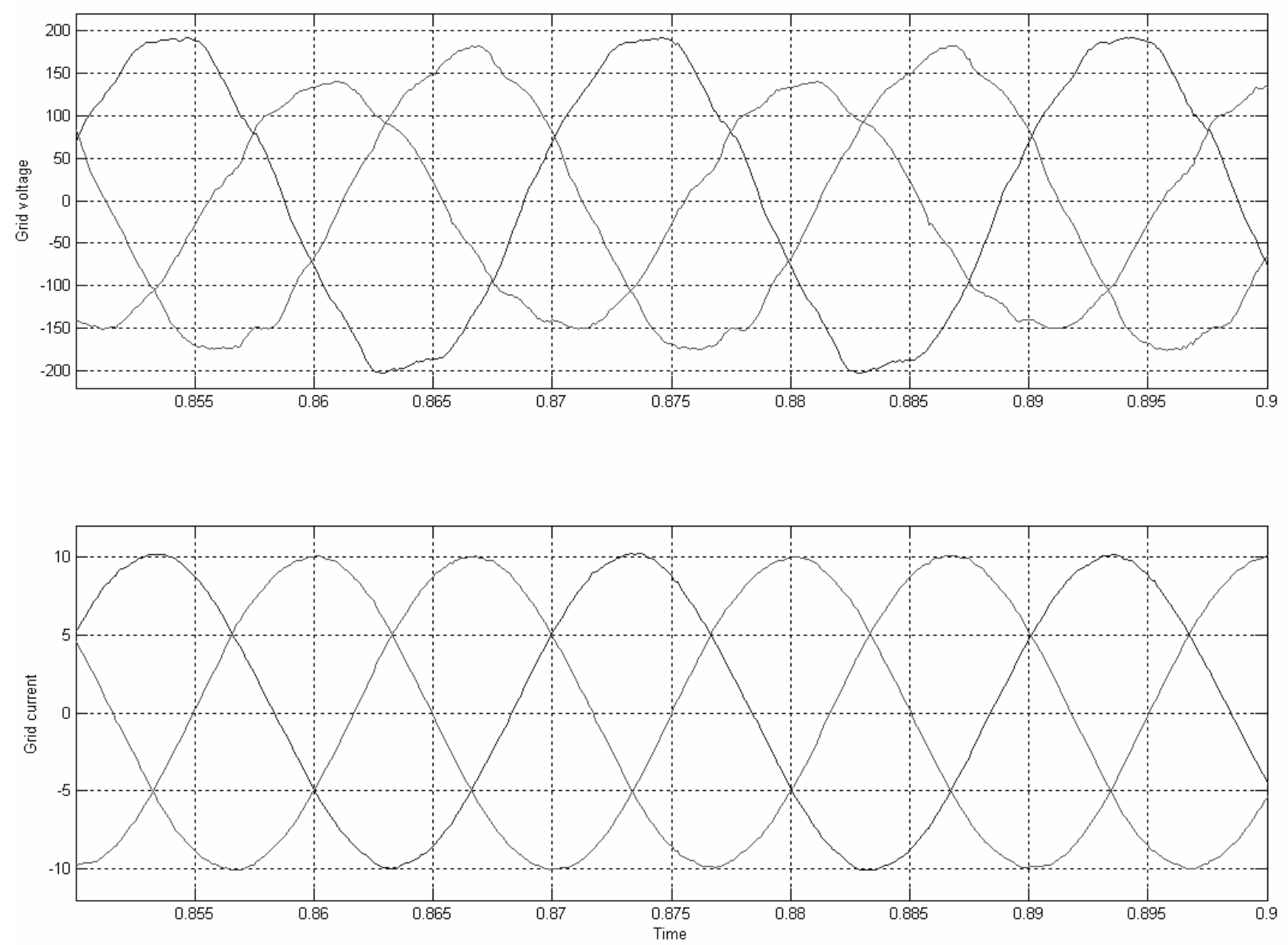

Fig. 7. Currents in positive SRF during voltage dip: a) conventional VOC, b) improved VOC 

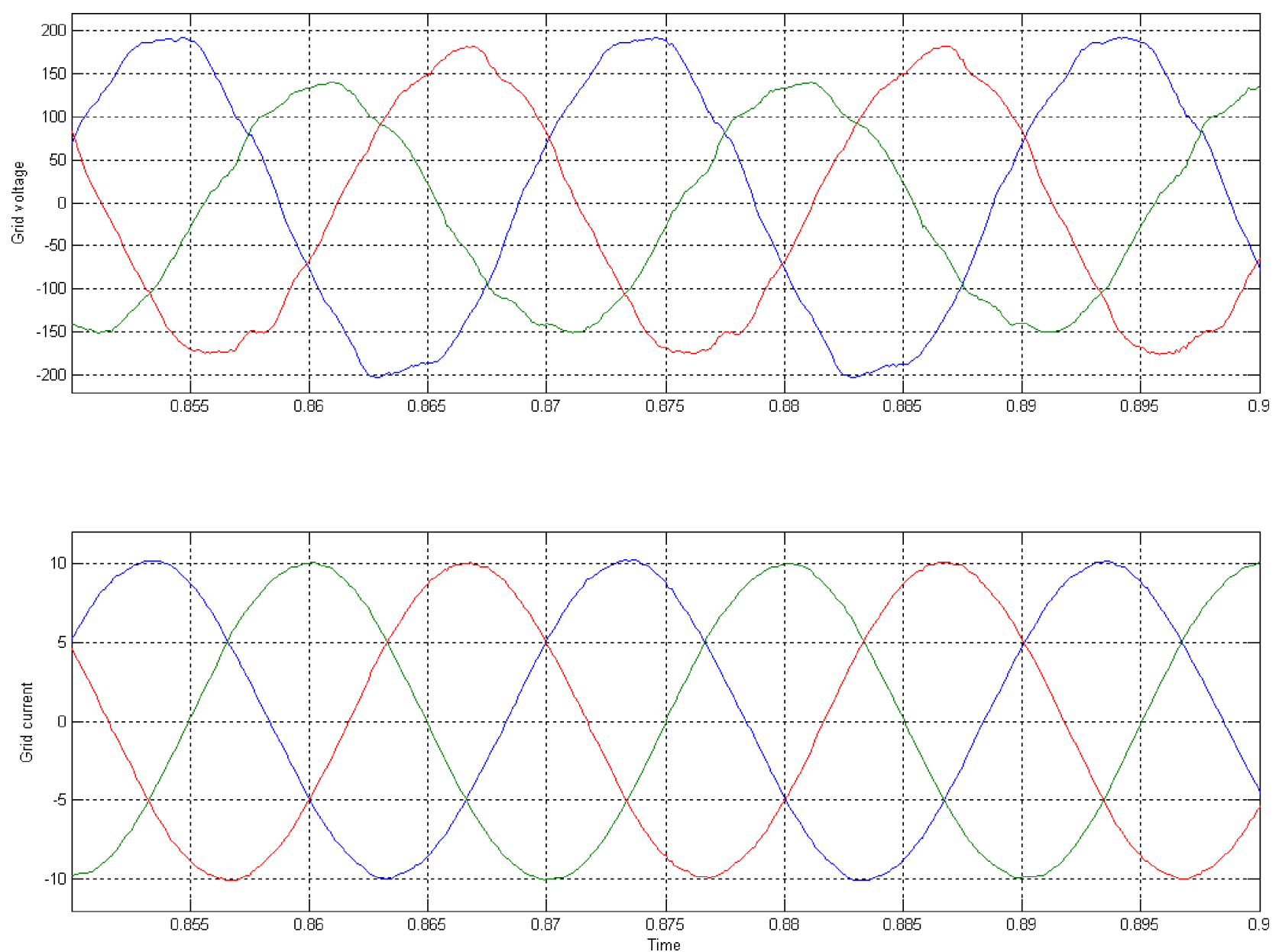

Fig. 8. Voltage and current shape during dip for improved VOC

\section{Summary and conclusions}

An improved Voltage Oriented Control (VOC) algorithm for AC-DC PWM active rectifier has been presented and investigated. The system is immune to grid voltage distortions as voltage dips and harmonics. The application of line voltage feedforward improves considerably compensation of positive sequence harmonic components and the Phase Locked Loop (PLL) algorithm generates undistorted phase information for control algorithm. Hence, the whole system is stable at every grid condition and forms sinusoidal-shape current independent of harmonics and negative components. Among important features of the system are:

- The shape of grid current remains sinusoidal (low THD);

- The order of current sequences remains unchanged;

- Extraction of current components allow to control positive and negative sequences independently to achieve proper controlling signals in the system; employing Delayed Signal Cancellation (DSC) algorithm cancels the $100 \mathrm{~Hz}$ component appearing during unbalanced voltage dips.

- Easy implementation in low cost microprocessor,

- Efficient higher harmonic compensation.

However, these advantages are occupied by a requirement of line voltage sensors.

\section{REFERENCES}

[1] M.H.J. Bollen, Understanding Power Quality Problems, IEEE Press, New Jersey, 2000.

[2] EN-50160, Voltage Characteristics of Electricity Supplied by Public Distribution Systems, CENELEC, Brussels, 1994.

[3] Grid Code, High and Extra High Voltage, E.ON Netz Gmbh, Bayreuth, 2006.

[4] M.P. Kazmierkowski, R. Krishnan, and F. Blaabjerg, Control in Power Electronics. Selected Problems, Academic Press, New York, 2002.

[5] M. Malinowski, M.P. Kazmierkowski, and A. Trzynadlowski, "A comparative study of control techniques for PWM rectifiers in AC adjustable speed drives", IEEE Trans. Power Electronics 18 (6), 1114-1118 (2003).

[6] M. Malinowski, M. Jasinski, and M.P. Kazmierkowski, "Simple direct power control of three-phase PWM rectifier using space vector modulation (DPC-SVM)", IEEE Trans. Industrial Electronics 51 (2), 447-454 (2004).

[7] P. Antoniewicz and M.P. Kazmierkowski, "Predictive direct power control of three-phase boost rectifier", Bull. Pol. Ac.: Tech. 54 (3), 287-292 (2006).

[8] P. Antoniewicz and M.P. Kazmierkowski, "Virtual-flux-based predictive direct power control of AC/DC converters with online inductance estimation", IEEE Trans. Industrial Electronics 55 (12), 4381-4390 (2008). 


\section{Control of PWM rectifier under grid voltage dips}

[9] M. Malinowski, M.P. Kazmierkowski, S. Hansen, F. Blaabjerg, and G.D. Marques, "Virtual-flux-based direct power control of three-phase PWM rectifiers", IEEE Trans. on Industry Applications 37 (4), 1019-1027 (2001).

[10] I. Etxeberria-Otadui, U. Viscarret, M. Caballero, A. Rufer, and S. Bacha, "New optimized PWM VSC control structure under unbalanced voltage transient", IEEE Trans. Industrial Electronics 54 (5), 2902-2914 (2007).

[11] G. Escobar, A. M. Stankovic, and P. Mattavelli, "An adaptive controller in stationary reference frame for d-statcom in unbalanced operation", IEEE Trans. Industrial Electronics 51 (2), 401-409 (2004).

[12] P. Rioual, H. Pouliquen and J.P. Louis, "Regulation of a PWM rectifier In the unbalanced network state using a generalized model", IEEE Trans. Power Electronics 11 (3), 495-502 (1996).

[13] M. Bongiorno, J. Svensson, and A. Sannino, "An advanced cascade controller for series-connected VSC for voltage dip mitigation", IEEE Trans. Industry Applications 44 (1), 187195 (2008).
[14] D. Santos-Martin, J. Rodriguez-Amenedo, and S. Arnalte, "Direct power control applied to doubly fed induction generator under unbalanced grid voltage conditions", IEEE Trans. Power Electronics 23 (5), 2328-2336 (2008).

[15] H. Song and K. Nam, "Dual current control scheme for PWM converter under unbalanced input voltage conditions", IEEE Trans. Industrial Electronics 46 (5), 953-959 (1999).

[16] D. Roiu, R. Bojoi, L.R. Limongi, and A. Tenconi, "New stationary frame control scheme for three phase pwm rectifiers under unbalanced voltage dips conditions", IAS '08. IEEE 1 , 1-7 (2008).

[17] G. Ledwich and T.A. George, "Using phasors to analyze power system negative phase sequence voltages caused by unbalanced loads", IEEE Trans. Power Systems 9 (3), 1226-1232 (1994).

[18] G. C. Paap, "Symmetrical components in the time domain and their application to power network calculations", IEEE Trans. Power Systems 15 (2), 522-528 (2000).

[19] J.M.Aller, A. Bueno, and T. Paga, "Power systems analyzing using space-vector transformation", IEEE Trans. Power Systems 17 (4), 957-965 (2002). 